\title{
Application of combined fracturing in carbonate reservoirs of an oil field
}

\author{
E.E. Ovsepian, S.V. Migunova \\ Saint Petersburg Mining University, Department of Transportation and storage oil and gas, , St \\ Petersburg, Russia
}

\begin{abstract}
This scientific work presents the design of combined acid fracturing in carbonate reservoirs of an oil field using mathematical modeling methods. An analysis of geological and technical actions was carried out, on the basis of which it was revealed that the previously used acid fracturing showed high efficiency, but at the same time there was a rapid rate of decline in production. In this regard, after studying various types of fracturing, combined acid fracturing is recommended to apply. It was found that the application of this method helps to increase the width of fracture and keeps it open, thereby compensating the lack of traditional acid fracturing.
\end{abstract}

\section{Introduction}

Today, most of the oil and gas reserves are hard to recover, as they are located in deposits confined to low-permeability and slightly drained reservoirs. Oil deposits in carbonate reservoirs contain $40-45 \%$ of world oil reserves, and they account for about $60 \%$ of world oil production.

As for the Russian Federation, in Samara, Tomsk, and Perm regions, and Udmurtia, these deposits contain, respectively, $40 \%, 50 \%, 60 \%$, and $72 \%$ of the total oil reserves.

Almost all oil reserves concentrated in carbonate reservoirs of the Russian Federation belong to the hard-to-recover category. To extract reserves of such categories, it is necessary to search for new technologies to increase the hydrocarbon recovery factor (HCF). Combined geological and technical actions can be more effective than conventional methods but are provided by studying the geological and geophysical features of the reservoir and the choice of technology.

One of the types of geological and technical actions aimed at increasing production rate is hydraulic fracturing, which has proved to be highly effective in many hydrocarbon fields, with a competent approach to and choice of the target. According to an estimation of specialists, currently, about a third of hard-to-recover oil reserves can be extracted using hydraulic fracturing with acid exposure (acid fracturing).

However, the application of traditional acid fracturing did not give high effectiveness on every field in the Samara region; fracture starts to close rapidly because the proppant is not in use. Therefore, this issue was presented in the scientific work "Cross-Linked AcidCarrying Proppant Fracturing" [1], where the authors showed a new method that was 
applied at the Tarim oilfield in China. Cross-linked acid with proppantwas used as the fracturing fluid, which compensated for the lack of traditional acid fracturing.

The purpose of this scientific work is to substantiate the effectiveness of combined acid fracturing in the conditions of heterogeneous carbonate reservoirs in the Samara region of the Russian Federation.

The main objectives of the research include:

- Studying and classification of existing hydraulic fracturing technologies

- Identifying the features of an oil field in conditions of carbonate reservoirs

- Substantiating the effectiveness of combined acid fracturing using mathematical modeling methods.

\section{Classification of fracturing technologies}

Hydraulic fracturing is a method of creating new fractures or expanding some existing in the formation. A fracture is created in a rock by injecting a viscous fluid at a rate and a pressure sufficient to split up the formation. Fracture height is mainly controlled by the stress contrasts in the bounding rock layers. Fracture length depends on the height containment and the leak-off properties of the fracturing fluid $[2,3]$.

Based on the studies of the accumulated experience in the application of various types of hydraulic fracturing according to foreign and national sources, the conditions for, and the advantages and disadvantages of their use, a classification of existing types of fracturing technologies are provided in Table 1.

Table 1.Fracturing technologies.

\begin{tabular}{|c|c|c|c|}
\hline Technology & Advantages & Disadvantages & Application area \\
\hline $\begin{array}{l}\text { Proppant fracturing } \\
\text { [4]. }\end{array}$ & $\begin{array}{l}\text { Longer crack retention } \\
\text { time; } \\
\text { The proppant } \\
\text { conductivity is } \\
\text { significantly higher than } \\
\text { the conductivity of acid- } \\
\text { etched fractures. }\end{array}$ & $\begin{array}{l}\text { Difficult to introduce } \\
\text { proppant into } \\
\text { carbonates; } \\
\text { Lack of predictability } \\
\text { of process; } \\
\text { More expensive } \\
\text { method compared to } \\
\text { acid fracturing. }\end{array}$ & $\begin{array}{l}\text { Homogeneous } \\
\text { terrigenous and } \\
\text { carbonate reservoirs. }\end{array}$ \\
\hline $\begin{array}{l}\text { Fracturing with } \\
\text { viscoelastic } \\
\text { diverting acid } \\
\text { (VDA). [5] }\end{array}$ & $\begin{array}{l}\text { Self-diverting acid } \\
\text { system; } \\
\text { Lack of residual collector } \\
\text { contamination; } \\
\text { Good zonal coverage. }\end{array}$ & $\begin{array}{l}\text { High cost; } \\
\text { Destruction of the } \\
\text { acid system in high- } \\
\text { temperature } \\
\text { reservoirs. }\end{array}$ & $\begin{array}{l}\text { Multilayer reservoirs } \\
\text { and reservoirs with } \\
\text { large production } \\
\text { intervals; } \\
\text { Wells with a damaged } \\
\text { formation zone. }\end{array}$ \\
\hline $\begin{array}{l}\text { Multi-stage } \\
\text { fracturing [6]. }\end{array}$ & $\begin{array}{l}\text { Increased reservoir } \\
\text { coverage compared to } \\
\text { fracturing methods in } \\
\text { vertical wells. }\end{array}$ & $\begin{array}{l}\text { Significantly higher } \\
\text { application costs. }\end{array}$ & $\begin{array}{l}\text { Horizontal wells; } \\
\text { Terrigenous and } \\
\text { carbonate reservoirs. }\end{array}$ \\
\hline Acid fracturing [7]. & $\begin{array}{l}\text { High penetration of acid } \\
\text { solution; } \\
\text { Wider fracture compared } \\
\text { to proppant fracturing; } \\
\text { Cleaning wellbore from } \\
\text { colmataging. }\end{array}$ & $\begin{array}{l}\text { Low conductivity; } \\
\text { Faster closing of } \\
\text { fractures compared to } \\
\text { proppant fracturing. }\end{array}$ & $\begin{array}{l}\text { Heterogeneous } \\
\text { formation (carbonate } \\
\text { and terrigenous) with } \\
\text { complex structure. }\end{array}$ \\
\hline $\begin{array}{l}\text { Combined acid } \\
\text { fracturing [8] }\end{array}$ & $\begin{array}{l}\text { The flow rate and } \\
\text { duration of production } \\
\text { are significantly higher } \\
\text { compared to } \\
\text { conventional acid }\end{array}$ & $\begin{array}{l}\text { High costs of raw } \\
\text { materials due to } \\
\text { using combined } \\
\text { methods of proppant } \\
\text { and acid fracturing. }\end{array}$ & $\begin{array}{l}\text { Heterogeneous } \\
\text { carbonate reservoirs } \\
\text { with hard-to-recover } \\
\text { reserves; } \\
\text { Successful use both in }\end{array}$ \\
\hline
\end{tabular}


Currently, there are many types of hydraulic fracturing. However, they each have their advantages and disadvantages. In the conditions of carbonate reservoirs, preference is given to acid fracturing, since the working fluid has a higher penetrating ability, and also when using hydrochloric acid, the bottomhole formation zone is cleaned of asphalt-resin-paraffin deposits and other clogging components.

\section{Identification of oil-field features}

The field, that is analyzing, locates in the Samara region of the Russian Federation. Data was provided by an oil and gas company developing this field.

In the case of applying to fracturea carbonate reservoir with a heterogeneous structure is considered (Figure 1). The object is characterized by a complex structure, stands out at the formation top of the Tournaistage. The depth of the formation is $1650 \mathrm{~m}$.

The stage is represented by limestones with interlayers of dolomites. Limestones in their main part are rather dense and hard. At the formation top, limestones are organogenic clastic, porous, and oil-saturated. The permeability of the reservoir is $0.013 \mu^{2}$, which, according to the classification, refers to good [9].

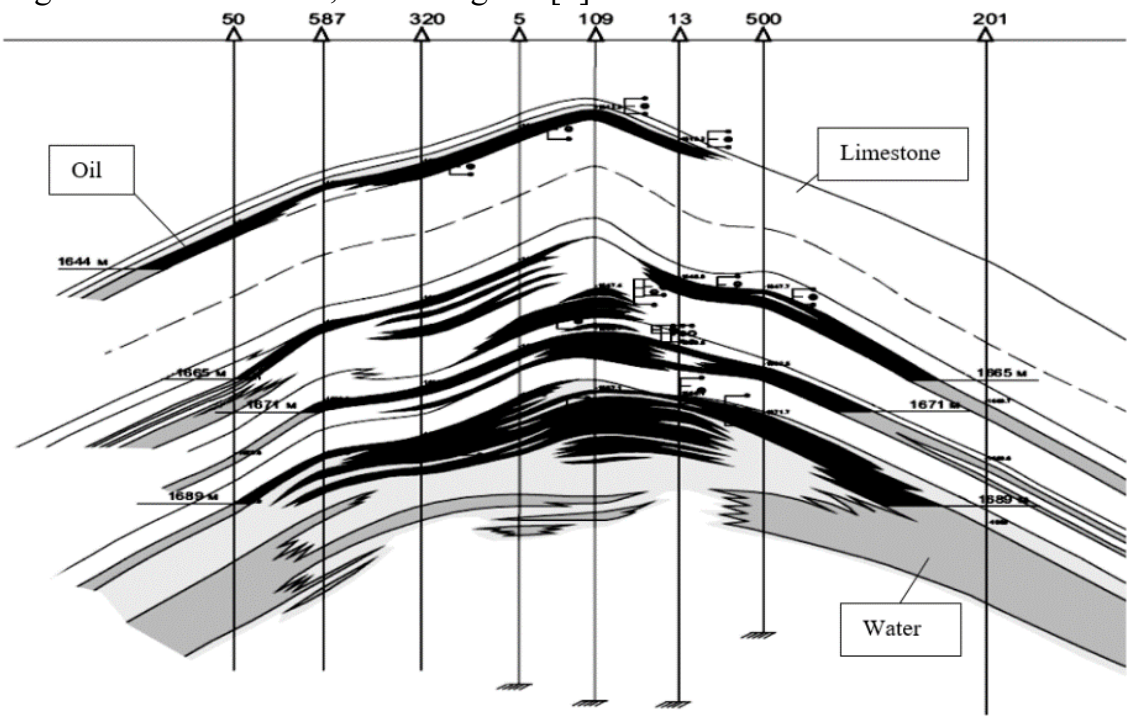

Fig.1. Geological structure of carbonate reservoir.

It is necessary to study the physicochemical properties of the formation fluid to determine the cause of the decline in the well productivity and to select the correct method of well stimulating. Properties were determined in a specialized laboratory.

The density of reservoir oil is $818 \mathrm{~kg} / \mathrm{m}^{3}$, bubble-point pressure is $5.36 \mathrm{MPa}$, the gas/oil ratio at a single degassing of reservoir oil is $0.0415 \mathrm{~m}^{3} / \mathrm{kg}$, the dynamic viscosity of reservoir oil is $4.59 \mathrm{mPa} \cdot \mathrm{s}$. The formation volume factor is 1.080 .

According to commercial quality, oil is considered sulfurous (mass sulfur content is $1.80 \%$ ), resinous $8.62 \%$, paraffinous $5.77 \%$, which creates a decline in production due to wellbore contamination. The volumetric recovery of distillation fractions upon $300^{\circ} \mathrm{C}$ is $44 \%$. 
The reservoir is characterized by a complex structure. The permeability of the reservoir is classified as average. Based on the composition of the reservoir oil, it can be concluded that the oil is sulfurous, resinous, and paraffinious, which greatly complicates production. However, based on the density of oil, it belongs to light oils, which creates extra problems with filtration in the formation.

\section{Technological rationale of combined acid fracturing}

\subsection{Selection of candidate well}

For hydraulic fracturing, certain conditions must be observed to achieve a technological effect:

- Availability of undeveloped hydrocarbon reserves

- Remoteness of the well from the oil water contact (OWC)

- The reservoir must have sufficient oil reserves

- Low productivity of the well

- Low water cut of the well.

After carrying outan analysis of the production well stock, a candidate well was selected for fracturing. On August 2019, the well had a low production index because of wellbore contamination (Skin-factor $=+3.5)$. Water-cut was low $(9.3 \%)$, which made it possible to apply fracturing. Figure 2 shows well characteristics.

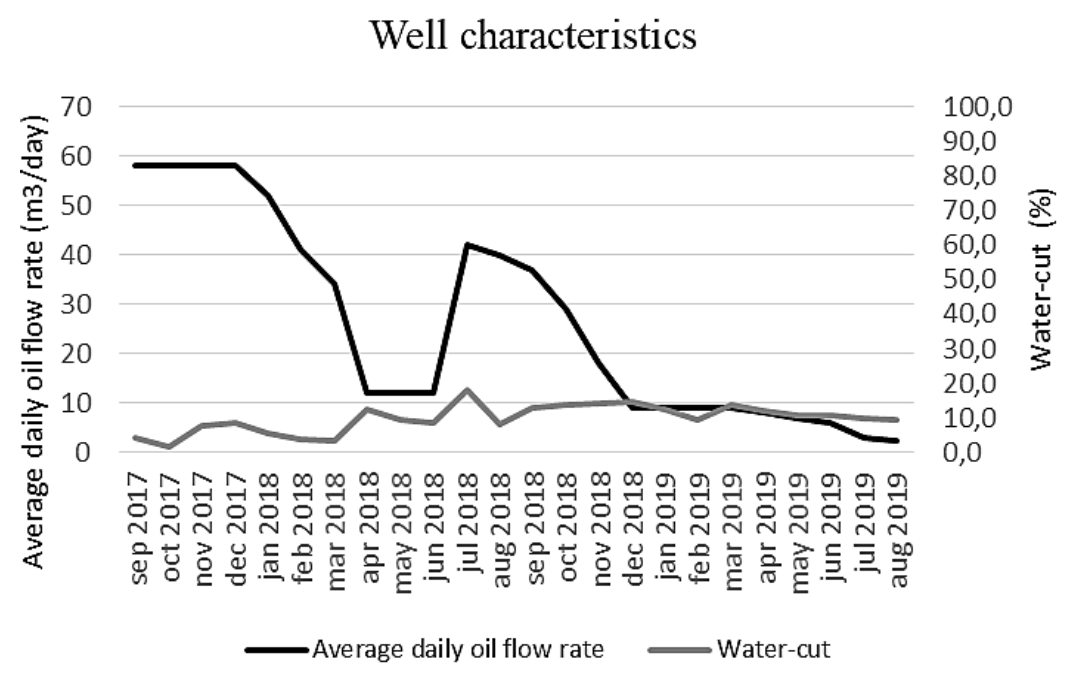

Fig. 2. Characteristics of the well.

\subsection{Features of combined acid fracturing}

Based on the considered reservoir conditions (heterogeneous carbonate reservoirs), hydraulic fracturing with acid exposure was chosen as the recommended technology [10].

The following factors suggest the use of acid fracturing [11]:

- Mostly naturally fractured carbonate formation, which can potentially lead to complicated fracturing e 
- Heterogeneous formation with bands of porosity and permeability that contribute to a higher degree of differential acid etching of the walls of destruction

- Good formation permeability but with existing damage of the formation.

Applying conventional acid fracturing did not bring high production effectiveness in other wells draining the given formation, since the absence of proppant leads to a quick closure of fractures. For this reason, it was recommended to apply combined acid fracturing (CAF).

A distinctive feature of $\mathrm{CAF}$ is the cross-linked acid carrying proppant solution (not just acid, as is the case with acid fracturing).

The advantage of CAF over conventional acid fracturing and proppant fracturing is that it incorporates all their best qualities: hydrochloric acid, which can dissolve carbonate rocks increasing the permeability of the fracture, and a proppant, which does not allow the fracture to close, thereby compensating the disadvantages of conventional acid fracturing. Proppant is the material that keeps the fracture open while maintaining its conductivity.

\subsection{Selection of the acid composition}

The selection of a proper fracturing fluid depends on many considerations, some of which are listed below [5]:

- Whether the fluid is safe to use and safe for the environment

- Whether the fluid is cost-effective

- Whether the fluid requires cross-linking to gel it up during the treatment and can then break easily to a low viscosity fluid once the treatment is over

- Whether the fluid is compatible with reservoir rocks and fluids

- Whether the fluid can break to low viscosity that helps flow back and clean up without leaving residuals to cause damage to the reservoir and proppant pack

- Whether the fluid can provide low wellbore friction and enough hydrostatic head to reduce surface pumping pressures

- Whether the fluid requires additives to help control fluid loss.

The use of hydrochloric acid to treat the formation causes several problems: high corrosiveness, high interfacial tension at the border with hydrocarbons; secondary sedimentation; increased reaction rate with water-saturated rock; sedimentation and emulsification with reservoir fluids: nteraction of hydrochloric acid with limestone: $2 \mathrm{HCl}$ $+\mathrm{CaCO}_{3}=\mathrm{CaCl}_{2}+\mathrm{H}_{2} \mathrm{O}+\mathrm{CO}_{2}$,

Interaction of hydrochloric acid with dolomite: $4 \mathrm{HCl}+\mathrm{CaMg}\left(\mathrm{CO}_{3}\right)_{2}=\mathrm{CaCl}_{2}+\mathrm{MgCl}_{2}+$ $2 \mathrm{H}_{2} \mathrm{O}+\mathrm{CO}_{2}$.

In order to minimize formation damage from the reaction products of hydrochloric acid with carbonate rocks, it is necessary to select the correct acid composition [6].

The selection of fracturing fluid is carried out in accordance with reservoir conditions (lithology, temperature, pressure, etc.), including on the basis of studies conducted at the Tarim oilfield. The compatibility of the selected fluid with the matrix of the reservoir and formation fluids is taken into account.

According to the results of the analysis, the following composition is recommended for use: viscosifier to obtain necessary viscosity to decrease leak-off and increase fracture length, crosslinking agent, demulsifier to prevent emulsification, corrosion inhibitor, ferrous stability, gel breaker.

\subsection{Combined acid fracturing treatment design}

Pad fluid, typically water-based, is injected into the well to create the desired fracture height, width, and length. Once the desired values of fracture are created, in two stages 
injection of cross-linked acid solution with proppant starts to etch the walls of the fracture and keep conductivity.

The first injection stage is a low proppant concentration $\left(\sim 300 \mathrm{~kg} / \mathrm{m}^{3}\right)$ and a high acid concentration $(15 \% \mathrm{HCl})$.

The second injection stage is a high proppant concentration $\left(\sim 600 \mathrm{~kg} / \mathrm{m}^{3}\right)$ and, as a result, the acid concentration $(10 \% \mathrm{HCl})$ decreases to reduce the etching effect on the proppant.

The next stage is the over flush. The purpose of the over flush is to displace acid from the wellbore and push it forward, thereby increasing the penetration distance. Thevolume of the over flush liquid should be increased by $20-30 \%$ compared to the volume of tubing. Table 2 shows the whole treatment design.

Table 2. Treatment design.

\begin{tabular}{ccc}
\hline Step & Fluid & Volume \\
\cline { 2 - 3 } & Cross-linked gelled water & 7 \\
\hline Pad & $15 \%$ HCI $+200 / 300$ \\
1-st acid stage & 20 \\
& $\mathrm{~kg} / \mathrm{m}^{3}$ proppant $16 / 30$ mesh \\
\hline 2-nd acid stage & $\begin{array}{c}10 \% \text { HCI }+500 / 600 \\
\mathrm{~kg} / \mathrm{m}^{3} \text { proppant } 12 / 18 \text { mesh }\end{array}$ \\
\hline Overflush & Water & 16.6 \\
\hline
\end{tabular}

\subsection{Calculation of fracture parameters}

To correctly model fracture parameters (length, width), it is necessary to take into account the dissolving ability of hydrochloric acid.

The created fracture length [7] is:

$$
l_{f}=\sqrt{\frac{V_{f} E}{5,6 h\left(1-v^{2}\right)\left(P_{f}-P_{h . p}\right)}}
$$

Where $E=$ Young's modulus, $\mathrm{MPa} ; h=$ net pay thickness, $\mathrm{m} ; V_{f}=$ volume of fluid to create and fill the crack with the solution; $v=$ Poisson's ratio; ${ }^{P_{f}}=$ hydraulic fracture pressure, $\mathrm{MPa}$; and $P_{h . p}=$ horizontal component of rock pressure, MPa.

Fracture width after interaction with acid was calculated by following formula (2), taking into account the volumetric dissolving power of the acid [8]:

$$
\omega_{f}=\frac{X V_{c a s}}{2 h l(1-\phi)},
$$

Where $V c a s=$ volume of the cross linked acid solution with proppant, $\mathrm{m}^{3} ; \phi=$ porosity of rock, $\%$; and $X=$ volumetric dissolving power of the acid. 


\subsection{Selection of the propping agent}

As a propping agent, a resin coated proppant with a density of $2920 \mathrm{~kg} / \mathrm{m}^{3}$, mesh 16/30 and $12 / 18$ was recommended for using. The main reason for choosing this proppant is its low solubility in acid.

According to the Carman-Kozeny model (3), the proppant fracture permeability is calculatedas [9]:

$$
k_{\text {prop }}=\frac{\phi_{\text {prop }}{ }^{3}}{36 C\left(1-\phi_{\text {prop }}\right)^{2}} d^{2},
$$

Where $d=$ the average grain diameter, $\mathrm{m} ; C=$ the Carman-Kozeny constant for spherical shape of grains; and $\phi_{\text {prop }}=$ proppant porosity, $\%$.

Based on proppant permeability, the dimensionless conductivity of created fracture is calculated by the following formula:

$$
C_{f}=\frac{k_{\text {prop }} \omega_{f}}{k_{f} x_{f}},
$$

Where $k_{f}=$ permeability of the formation, $\mu \mathrm{m}^{2}$; and $x_{f}=$ fracture half-length, $\mathrm{m}$.

To calculate the skin factor, which shows the degree of contamination of the bottomhole zone, it is necessary to calculate the effective wellbore radius (5):

$$
r_{e f}=r_{c}+\frac{x_{f}}{2\left(1+\left(\frac{C_{f}}{1,7}\right)^{-1,01}\right)},
$$

The skin factor is estimated as follows:

$$
S=-\ln \left(\frac{r_{e f}}{r_{w}}\right),
$$

Where $r_{w}=$ well radius, $\mathrm{m}$. 


\subsection{Results of application of combined acid fracturing}

The studies compared the effectiveness of CAF and conventional proppantfracturing (PF).

The results are presented in Figure 4.
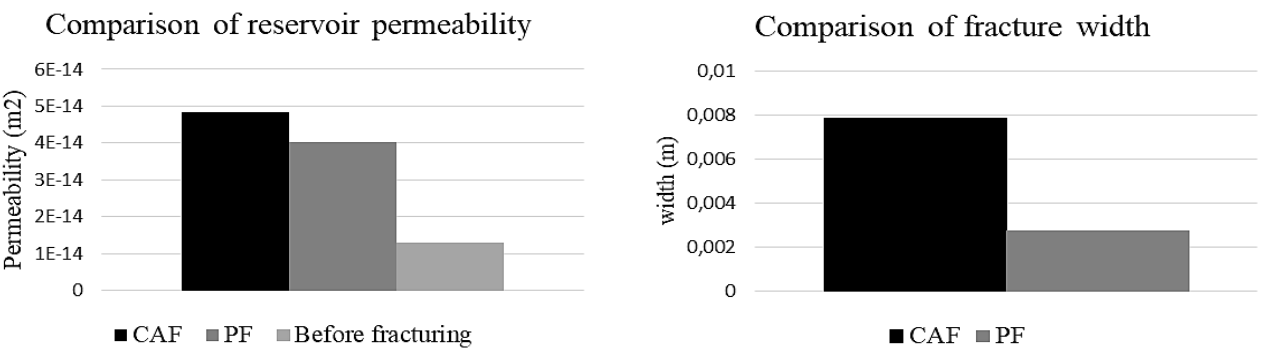

Fig. 4. Results of CAF and PF application.

The application of CAF improved the reservoir properties. The degree of contamination of the formation pay zone significantly decreased. The value of skin factor after CAF changed from +3.5 to -4.3 .

Daily production rate is calculated usingthe Dupuis formula:

$$
Q_{C A F}=\frac{2 \pi k f h}{\mu \beta} \cdot \frac{\Delta P}{\ln \frac{R_{C}}{r_{w}}+S},
$$

Figure 5 shows results after applying $\mathrm{CAF}$ and $\mathrm{PF}$.

Comparison of flow rate after $\mathrm{CAF}$ and $\mathrm{PF}$ application

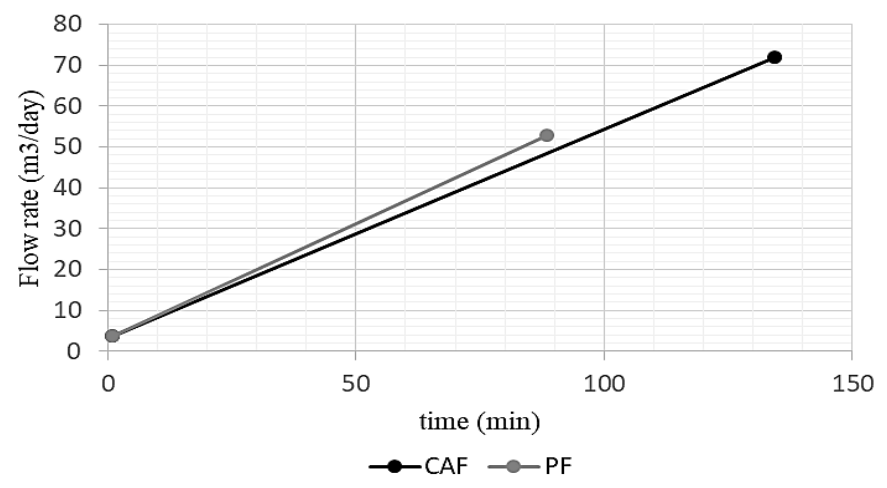

Fig. 5. Comparison of the flow rate of the well afterCAF and PF.

\section{Conclusions}

Presently, various types of hydraulic fracturing are used. Hydraulic fracturing was classified with highlighting its advantages, disadvantages, and the application area. 
When we are talking about fracturing methods, it is necessary to speak about environmental problems. The environment can be contaminated during fracturing with fluids that remain at the end of the process or spill due to rough handling. Damage to the lands can be caused by aggregates, sand mixers, tank trucks, and other special equipment.

To prevent environmental pollution during CAF, the following main activities shall be carried out:

- The remains of unused isotopes, as well as the liquid after rinsing tanks and pumps exposed to isotopes, should be diluted with water to a safe concentration and buried at a specially designated place.

- In the event of an uncontrolled flowing occurrence, an earthen bank to limit the possibility of spreading of formation fluid over a large area must be urgently built.

- The remains of unused isotopes, as well as the liquid after rinsing tanks and pumps exposed to isotopes, should be diluted with water to a safe concentration and buried at a specially designated place.

It has been established, that the reservoir in this field is characterized by a complex structure. In terms of component composition, reservoir oil is sulfurous, resinous, and paraffinious, which greatly complicates production.

It was shown that under conditions of carbonate reservoirs, the highest technological efficiency can be obtained due to combined acid fracturing since the working fluid has a higher penetrating ability and also due totheproppant that does not allow the fracture to close rapidly. Based on the results of mathematical modeling, it was found that in the conditions of carbonate heterogeneous reservoirs, the calculated well production rate may increase by 19 times.

\section{References}

1. C. Mingguang, Z.Raoyun,W. Liao, Y. Zhanwei,X. Guowe, H. Longcang, Cross-Linked Acid, (2018).

2. L. Kalfayan, Carbonate fracture acidizing: systems and procedures, Production enhancement with acid stimulation: 169-178 (2008)

3. A. Mazo, Superelements. Modeling the development of oil fields: monograph: 113120.(2020).

4. Carrying Proppant Fracturing. International Journal of Innovative Studies in Sciences and Engineering Technology (IJISSET): 1-5.(2020).

5. J. Hamed, J. Moghadasi, D.G. Petrakov, V.T. Litvin, P.V. Roshin, A.N. Kuznetcova, Self-diverting emulsified acid for stimulation of Iranian Ab-Teymur carbonate reservoir: European Association of Geoscientists and Engineers: EAGE, 79, 1-4 (2017).

6. D.A. Martyushev, Improvement of the geological and hydrodynamic model of a carbonate oil object by taking into account the permeability anisotropy parameter, ZapiskiGornogoInstituta,243(2020).

7. H.H. Jafarpour, Increasing the stimulation efficiency of heterogeneous carbonate reservoirs by developing a multi-bached acid system. Journal of Petroleum Science and Engineering: 172, 50-59.(2018).

8. A.M. Shagiakhmetov, D.G. Podoprigora, A.V. Terleyev, The study of the dependence of the rheological properties of gel-forming compositions on the crack opening when modeling their flow on a rotational viscometer. Periódico Tchê Química, 17, 933 939(2020). 
9. D.G. Podoprigora, L.A. Saychenko, Development of acid composition for bottom-hole formation zone treatment at high reservoir temperatures. Espacios: 48 (38), $32-$ 42.(2017).

10. I.T. Mischenko, Evaluations in oil production(Publishing house Nedra,1989).

11. B.B. Williams, J.L. Gidley, Acidizing fundamentals. SPE monograph series, 6: 114 (1979). 